\title{
Treatment of a Basilar Artery Occlusion with Intra-arterial Thrombolysis in a 3-year-old Girl
}

\author{
Archit Bhatt - Bharath Naravetla · Muhammad U. Farooq · Arshad Majid • \\ Mounzer Kassab · Rishi Gupta
}

Published online: 19 April 2008

(C) Humana Press Inc. 2008

\section{Erratum to: Neurocrit Care}

\section{DOI 10.1007/s12028-008-9086-7}

The authors of this article are Archit Bhatt, Bharath Naravetla, Muhammad U. Farooq, Arshad Majid, Mounzer Kassab, and Rishi Gupta.

The online version of the original article can be found under doi:10.1007/s12028-008-9086-7.

\footnotetext{
A. Bhatt · B. Naravetla · M. U. Farooq · A. Majid . M. Kassab - R. Gupta

Department of Neurology and Ophthalmology, Division of Cerebrovascular Diseases, Michigan State University, East Lansing, MI, USA

R. Gupta $(\bowtie)$

Cerebrovascular Center, The Cleveland Clinic Foundation, 9500 Euclid Avenue, S80, Cleveland, OH 44195, USA

e-mail: guptar@ccf.org
} 